\title{
Fagoterapia: uma opção de controle biológico para a salmonelose aviária
}

\section{Phage therapy: an option of biological control for avian salmonelosis}

\section{Resumo}

Com a grande expansão da indústria avícola, a salmonelose tornou-se fator limitante na criação de aves, pois as perdas econômicas estão presentes em todas as fases. O aumento mundial da resistência bacteriana tornou necessária a busca por alternativas para controle desta doença fazendo ressurgir a fagoterapia como opção. O presente artigo revisa o fenômeno da bacteriofagia voltado para sua aplicação no controle da salmonelose aviária, usando como modelo os conhecimentos sobre o bacteriófago P22.

\section{Summary}

With the enormous expansion in the poultry industry, salmonellosis became a limiting factor on avian production, because of the important economic losses during the production stages. The worldwide increase in bacterial resistance stimulated the search for alternative strategies to control the disease and so phagoteraphy has been reconsidered as a therapeutic option. This article reviews the phenomenon of bacteriophagia focusing on its use for the control of avian salmonellosis, using the P22 bacteriophage as a model. 
Guilherme Augusto Marietto-Gonçalves ${ }^{1}$

Raphael Lucio Andreatti Filho ${ }^{2}$
Laboratório de Ornitopatologia, Departamento de Clínica Veterinária, FMVZ-UNESP, Caixa Postal 560, CEP 18618-000, Distrito de Rubião Júnior, Botucatu-SP, tel./fax: (14) 3811-6293. 西 gmarietto_ornito@fmvz.unesp.br

\section{Introdução: Salmonelose e sua relação com a avicultura}

Apesar da evolução da avicultura industrial, a salmonelose ainda é fator limitante na criação de aves, ocupando uma posição de destaque devido às perdas econômicas que abrangem desde a produção do frango até o consumo final dos subprodutos avícolas. Salmonelose é o termo usado para doenças agudas ou crônicas causadas por bactérias pertencentes ao gênero Salmonella (GAST, 1997). As aves, uma vez contaminadas, tornam-se portadoras intestinais e eliminam o agente nas fezes por longos períodos de tempo e assim, a bactéria consegue alcançar o abatedouro comprometendo toda a linha de produção. As implicações epidemiológicas e econômicas das infecções alimentares em humanos podem alcançar grande magnitude, onde a crescente incidência é associada à ingestão de produtos de origem avícola contaminados e/ou indevidamente preparados, visto que as aves são consideradas reservatórios de Salmonella spp. (GAST, 1997; TOOD, 1997).

A Salmonella é um bastonete Gram-negativo, pertencente à família Enterobacteriaceae. São reconhecidas três espécies pertencentes ao gênero: S. subterranea, isolada do solo; S. bongori, isolada de animais de sangue frio; e $S$. enterica, isolada de animais de sangue quente. Esta última espécie apresenta seis subespécies (enterica, salamae, arizonae, diarizonae, houtenae e indica) e aproximadamente 2.500 sorotipos, incluindo Pullorum e Gallinarum específicos de aves (JUDICIAL COMMISSION, 2005; SHEBOLINA et al., 2004; ANDREATTI FILHO, 2007; BERCHIERI JÚNIOR \& FREITAS NETO, 2009).

1 Médico Veterinário/ Biólogo, Msc.; Departamento de Clínica Veterinária, FMVZ-UNESP/Botucatu-SP, gmarietto_ornito@fmvz.unesp.br

2 Médico Veterinário, Prof. Ass. Dr.; Departamento de Clínica Veterinária, FMVZ-UNESP/Botucatu-SP, andreatti@fmvz.unesp.br 
Em aves, a $S$. enterica subespécie enterica causa três formas distintas de salmonelose. A pulorose é causada pelo sorotipo Pullorum, sendo uma doença que acomete principalmente pintos (aves adultas dificilmente manifestam sintomatologia) com um alto índice de mortalidade em aves recém-nascidas. Já as aves jovens, apresentam uma mortalidade variável, sendo comum a regressão da doença, dessa maneira, as aves podem se tornar portadoras assintomáticas pós-infecção. O tifo aviário é causado pelo sorotipo Gallinarum, sua ocorrência é mais comum em aves adultas (quando acomete aves jovens o tifo pode ser confundido com pulorose) e pode haver perda de até $80 \%$ do plantel em surtos graves. O paratifo é a manifestação clínica de qualquer sorotipo de Salmonella que não seja Pullorum e Gallinarum. O paratifo costuma apresentar uma infecção branda ou clinicamente imperceptível em aves adultas, podendo haver mortalidade em pintos, conforme a virulência do sorotipo envolvido, destacando-se os sorotipos Enteritidis e Typhimurium (BERCHIERI JÚNIOR e FREITAS NETO, 2009).

Historicamente, o isolamento de Salmonella em granjas avícolas é comum no Brasil (SILVA e DUARTE, 2002). Entre os anos de 1970 e 1990 os sorotipos mais prevalentes foram o Anatum e Typhimurium e entre os anos de 1991 e 1995 o Enteritidis começou a ser isolado principalmente em ovos, aves (matrizes) e amostras ambientais (TAUNAY et al., 1996; TAVECHIO et al., 1996). Após o ano de 1997, já era comumente isolado (SILVA e DUARTE, 2002) tendo predominado entre todos os sorotipos (ANDREATTI FILHO et al., 2001).
O sorotipo Enteritidis é comum em aves. Depois de Pullorum e Gallinarum, ele foi, ao lado de Typhimurium, o mais importante causador de infecções paratifóides em aves nos EUA, sendo os principais responsáveis por infecções alimentares no homem (BERCHIERI JÚNIOR e FREITAS NETO, 2009; CENTERS OF DISEASES AND CONTROL, 2009). Outros sorotipos comumente isolados em aves são Agona, Anatum, Cubana, Hadar, Heidelberg, Infantis, Mbandaka, Montevideo e Senftenberg (ANDREATTI FILHO, 2007; BERCHIERI JÚNIOR e FREITAS NETO, 2009).

$\mathrm{O}$ uso indiscriminado de antibióticos em aves ao longo dos anos propiciou a manutenção de lotes positivos para Salmonella, sendo que o aumento mundial da resistência bacteriana fez com que se procurassem alternativas no controle desta doença, ressurgindo assim a fagoterapia como opção (JOERGER, 2003; SULAKVELIDZE, 2005; SKURNIK e STRAUCH, 2006; ANDREATTI FILHO et al., 2007).

\section{Bacteriofagia}

O fenômeno de bacteriofagia foi observado em 1915 por Frederick W. Twort e, paralelamente, em 1917 por Félix d'Herelle, sendo melhor compreendido por André Gratia em 1921, pois até então não se sabia exatamente a natureza dos bacteriófagos (BIER, 1984; DUBLANCHET e FRUCIANO, 2008), também chamados de fagos. Hoje, sabe-se que os fagos são vírus que infectam bactérias, sendo conhecidos cerca de 2.700 fagos, cuja morfologia varia entre as formas cúbica, filamentosa ou pleomórfica (Figura 1),

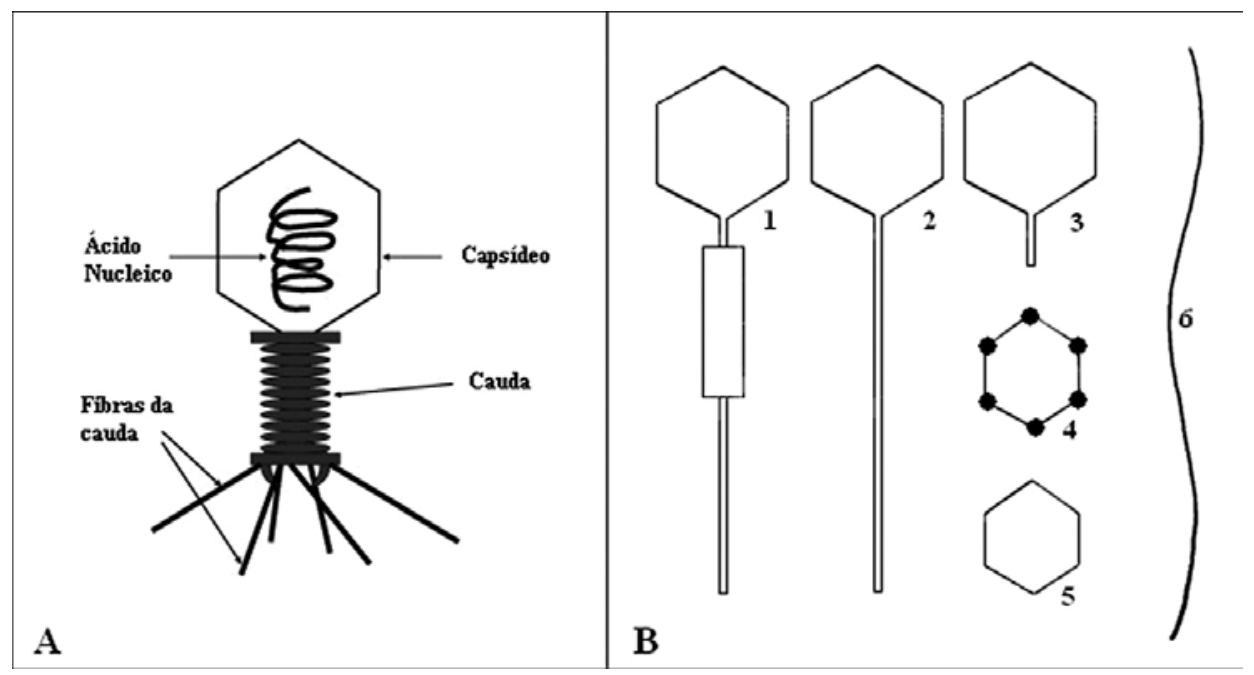

FIGURA 1 - A) Estruturas comuns dos bacteriófagos; B) Características morfológicas específicas dos diferentes tipos de bacteriófagos: 1. Capsídeo com cauda contrátil; 2. Capsídeo com cauda rígida; 3. Capsídeo com cauda curta; 4. Capsídeo grande e sem cauda; 5. Capsídeo pequeno e sem cauda; 6. Filamento flexível sem capsídeo. Adaptado de Bradley (1973) e Hanlon (2007). 
contendo DNA de fita dupla ou RNA de fita simples em sua carga genética (BRADLEY, 1967; BIER, 1984; ACKERMANN, 1987). Os fagos são taxonomicamente organizados na ordem Caudovirales, vírus com presença de cauda, e distribuídos em 13 famílias com características morfológicas e genomas distintos (Tabela 1) (NELSON, 2004; HANLON, 2004).

Do ponto de vista de infecciosidade e das relações com o hospedeiro, dois tipos de fagos são reconhecidos: o lítico, que no final do seu período de incubação causa o rompimento da célula hospedeira; e o lisogênico, que apresenta uma infecção inaparente (YOUNG, 1992; HANLON, 2005). Para ambos os tipos a infecção se inicia com a adsorção e introdução do genoma fágico no interior da bactéria hospedeira. $\mathrm{O}$ fago de ciclo lítico segue por um período vegetativo, onde ocorre a replicação genômica e o encapsulamento das progênies, seguido da lise celular, onde ocorre a liberação das progênies infectantes. Já o fago de ciclo lisogênico incorpora o seu genoma ao bacteriano (recebendo o nome de profago) e se mantém inativo. Quando a célula hospedeira se replica, o profago é repassado para as células filhas (processo chamado de lisogenia) e após uma (até várias) replicação, o profago pode ser estimulado, desprendendo-se do genoma bacteriano e iniciando um ciclo lítico (LENSKI, 1988 HANLON, 2005). O quadro 1 apresenta as fases do ciclo lítico conforme Bull et al. (2004).

\begin{tabular}{ll} 
Corticoviridae & Capsídeo icosaédrico de parede lipídica \\
\hline Cystoviridae & Capsídeo icosaédrico com envelope lipídico \\
\hline Fuselloviridae & $\begin{array}{l}\text { Pleomórfico, com envelope lipídico e sem } \\
\text { capsídeo }\end{array}$ \\
\hline Lipothrixviridae & Envelope lipídico filamentoso \\
\hline Myoviridae & Cauda longa e contrátil \\
\hline Plasmaviridae & $\begin{array}{l}\text { Pleomórfico, com envelope lipídico e sem } \\
\text { capsídeo }\end{array}$ \\
\hline Podoviridae & Cauda curta e não contrátil \\
\hline Rudiviridae & Bastonete com formato helicoidal \\
\hline Siphoviridae & Cauda longa e não contrátil \\
\hline Tectiviridae & $\begin{array}{l}\text { Capsídeo icosaédrico com uma vesícula } \\
\text { lipoproteica interna }\end{array}$ \\
\hline
\end{tabular}

\section{RNA DE FITA SIMPLES}

\begin{tabular}{ll} 
Inoviridae & Bastonete com simetria helicoidal \\
\hline Leviviridae & Capsídeo semi-icosaédrico \\
\hline Microviridae & Capsídeo icosaédrico \\
\hline
\end{tabular}

TABELA 1 - Descrição das famílias de bacteriófagos (HANLON, 2007).
O ciclo lítico pode ser dividido em três fases (Figura I). A primeira fase é a de dispersão (D), que é relativa a liberação de fagos no ambiente por um hospedeiro no intuito da infecção de novos hospedeiros. O tempo deste período é dependente de dois fatores: abundância de hospedeiros susceptíveis e o índice de adsorção dos fagos ao entrarem em contato com o hospedeiro. O fago pode desenvolver um alto ou baixo índice de adsorção e assim influencia D, mas a abundância de hospedeiro também é importante para D, por controlar o limite de fagos. Ou seja, D é afetado pelos índices de fagos e hospedeiros no ambiente. A segunda fase é a juvenil (J), que inicia com o momento da infecção e termina quando as primeiras partículas fágicas infectantes são criadas nos interior do hospedeiro. O período deste intervalo é dependente do índice de expressão do genoma fágico, que é determinado pela combinação do estado de fisiológico da célula hospedeira e o genoma do fago.

A terceira fase é a adulta (A), que inicia com o surgimento das primeiras partículas fágicas infectantes e termina com o rompimento da célula hospedeira (lise). Durante este período o número de partículas fágicas infectantes dentro da célula aumenta gradativamente. $\mathrm{O}$ acúmulo de partículas fágicas é linear até o término deste período, sendo suprimido após a lise. Há obviamente um limite entre a linearidade e o número final de progênie dos fagos na célula hospedeira, mas estes limites ainda não foram determinados. O declive de aumento linear das partículas fágicas variam entre as espécies de fagos, como também conforme o estado fisiológico da célula hospedeira.

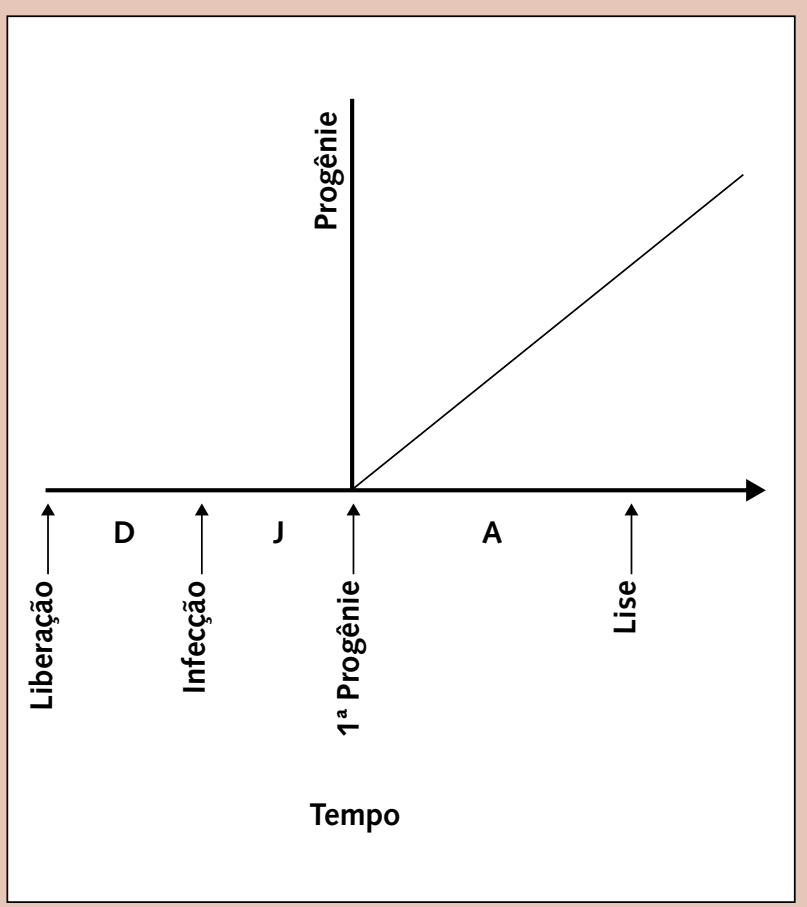

FIGURA I - Adaptado de Bull et al. (2004)

QUADRO 1 - O ciclo lítico dos fagos líticos apresenta três fases distintas. 


\section{Fagoterapia}

Fagos são predadores naturais de bactérias, comumente encontrados no ambiente e seu uso como biocontrolador é uma boa opção para a redução de Salmonella (ROHWER e EDWARDS 2002; ATTERBURY et al., 2007). Os fagos são específicos no que concerne à célula hospedeira, sendo que para cada espécie de bactéria existem fagos específicos que só causam danos à sua própria célula hospedeira, não causando danos às outras espécies bacterianas (MAYR e GUERREIRO, 1981).

A utilização terapêutica de fagos (fagoterapia) foi primeiramente proposta e efetuada com sucesso por d'Herelle (DUBLANCHET e FRUCIANO, 2008), mas com a descoberta dos antibióticos e quimioterápicos, acabou sendo esquecida, com seu uso limitado aos estudos de virologia (MAYR e GUERREIRO, 1981) e, mais recentemente, têm sido empregados para o monitoramento e a identificação de microrganismos (REES e VOORHEES, 2005; MANDILARA et al., 2006). A fagoterapia voltou a ser estudada recentemente com grande êxito, sendo muito discutida e defendida pela comunidade científica como o futuro do combate às infecções bacterianas (PIRISI, 2000; KERR, 2003; BROXMEYER, 2004; BRADBURY, 2004; SULAKVELIDZE, 2005; MATTEY e SPENCER, 2008).

Os estudos recentes ressaltam diversas vantagens da fagoterapia, como: i) eficiência contra bactérias patogênicas resistentes à antimicrobianos, devido à indução da bacteriólise, que difere completamente da ação destes; ii) não há infecção por outras bactérias, pois bacteriófagos são hospedeiro-específico; iii) capacidade de responder rapidamente à formação de fago-resistência do hospedeiro, pelo fato dos bacteriófagos também apresentarem a capacidade de sofrer mutação; iv) baixo custo de desenvolvimento, a pesquisa de procedimentos fagoterápicos é mais barata que a de desenvolvimento de novos antimicrobianos; v) os bacteriófagos não afetam células eucarióticas, onde efeitos colaterais do seu uso são incomuns (MATSUZAKI et al., 2005); vi) são onipresentes na natureza, comumente isolados em coleções hídricas, solo e em matéria orgânica (ROHWER e EDWARDS, 2002; ANDREATTI FILHO et al., 2007); e vii) seu cultivo é fácil, pois sua cultura é baseada na manutenção da bactéria hospedeira por métodos microbiológicos tradicionais (MATSUZAKI et al., 2005).

A fagoterapia já foi avaliada com êxito no tratamento de Acinetobacter baumanii, Pseudomonas aeruginosa, Staphylococcus aureus (SOOTHILL, 1992), Vibrio vulnificus (CERVENY et al., 2002), Enterococcus faecium (BISWAS et al., 2002) Bacillus anthracis (Schuch et al., 2002) e Escherichia coli patogênica em aves, ratos, no homem e em bezerros com redução de sintomatologia e da mortalidade (BARROW et al., 1998; BRÜSSOW, 2005; HUFF et al., 2002; HUFF et al., 2005).

\section{Ação fágica em Salmonella}

A infecção fágica é iniciada com a identificação e fixação do fago (adsorção) na superfície da célula hospedeira (BERGET e POTEETET, 1980; LENTZ, 1990). Os fagos utilizam diferentes tipos de sítios receptores para adesão que variam entre proteínas, oligossacarídeos, ácido teicoico, peptideoglicanos ou lipopolissacarídeos presentes nos componentes da superfície celular da bactéria hospedeira (LENSKI, 1988).

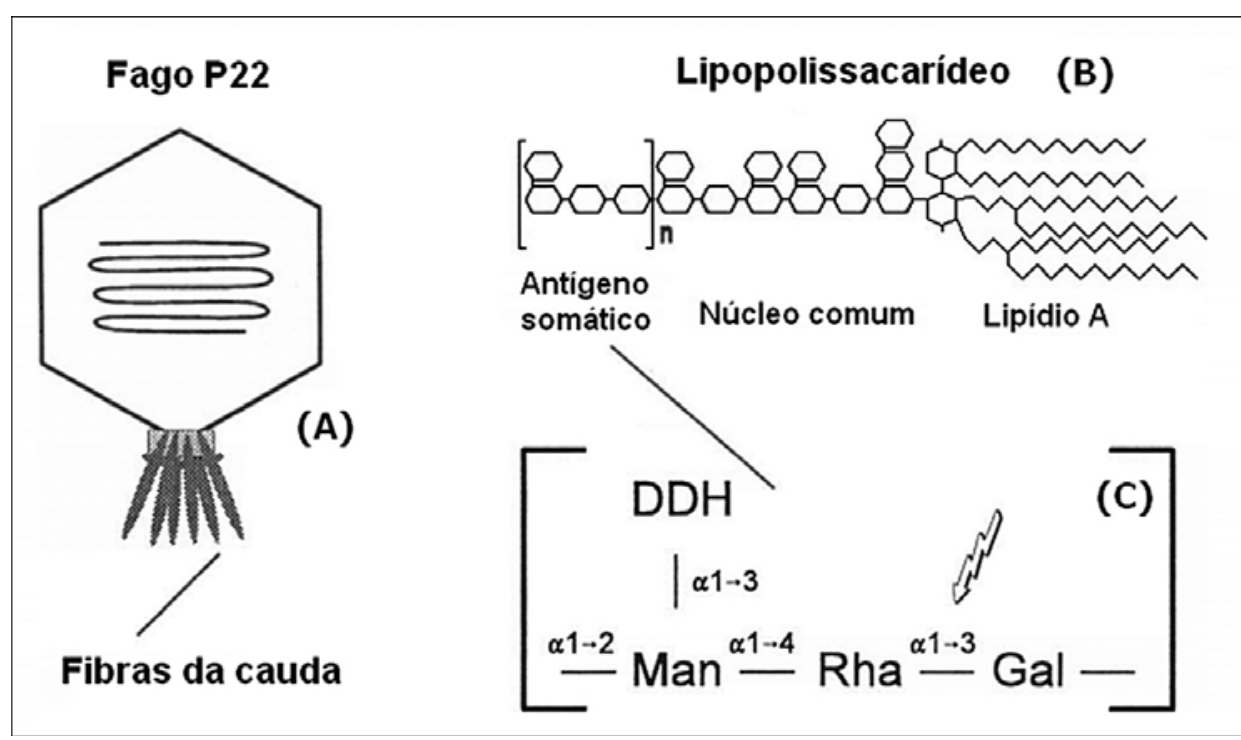

FIGURA 2 - A) Morfologia do fago P22; B) Representação esquemática do antígeno somático dos sorotipos de Salmonella pertencentes aos sorogrupos A, B1 e D1; C) Ponto de clivagem usado pelo P22 para realizar a adsorção. Adaptado de Baxa et al. (1996). 
O fago P22 é um fago lambdoide da família Podoviridae que parasita Salmonella enterica subespécie enterica. Muitos vírus de animais utilizam os oligossacarídeos de superfície como receptores para realizar a adsorção. Sua adesina é uma proteína homotrimérica de $215 \mathrm{kDa}$ localizada na ponta da cauda, sendo que existem seis fibras caudais (Figura 2-A) de $13 \eta \mathrm{m}$ fixadas em um único vértice do capsídeo (ISRAEL, 1978; BAXA et al., 1996).

Por meio da cauda, o P22 reconhece a sequência do antígeno somático na membrana lipopolissacarídica dos sorovares de $S$. enterica pertencentes aos sorogrupos A, B1 e D1. Seus antígenos somáticos apresentam em comum uma sequência trissacarídica em cadeia de unidades repetitivas de $\alpha$-D-manose- $(1 \rightarrow 4)-\alpha-L$-raminose- $(1 \rightarrow 3)-\alpha$ D-galactose- $(1 \rightarrow 4)$, diferindo apenas na dideoxihexose localizada no C-3 da manose (Figura 2-B) (BAXA et al., 1996). A cauda do P22 possui ação de endoglicosidase, responsável pela clivagem e hidrólise dos polissacarídeos do antígeno somático nas ligações raminose-galactose $a$ $(1 \rightarrow 3)$-glicosídicas (Figura 2-C) e produzindo dímeros de unidades repetitivas do produto principal, sendo que esse sistema receptor-inativador é comum em bacteriófagos polissacarídeos-específicos (LINDBERG, 1977; BERGET e POTEETET, 1980). Uma vez iniciado, esse processo é irreversível (ISRAEL, 1978).

A lise fágica é mediada por endolisinas, que podem ser de vários tipos enzimáticos (lisozimas, amidases e transglicosilases). Atacam sítios glicosídicos (lisozimas e transglicosilases) ou sítios peptídicos (amidases) e quando associados conferem maior rigidez mecânica na degradação da parede peptideoglicânica das bactérias. Estas enzimas são utilizadas tanto para a invasão na célula hospedeira, quanto para a liberação das progênies (YOUNG, 1992).

Em fagos lambdoides os genes responsáveis pela produção de enzimas são transcritos por um único promotor designado PR'. O cistron promotor-proximal de transcrição é constituído pelos genes de lise $S, R, R z$ e Rz1, que também são necessários para a formação do capsídeo e da cauda durante a replicação intracelular (HERSKOWITZ e SIGNER, 1970; DANIELS et al., 1983). O grupo gênico $\mathrm{SRRz}$, contém o fragmento EcoRI-ClaI (YOUNG, 1992), usado rotineiramente como um cassete de lise celular em técnicas laboratoriais (GARRET et al., 1981; CRABTREE e CRONAN JÚNIOR, 1984; JANG et al., 2007).

$O$ gene $\mathrm{R}$ codifica a transglicosilase (também conhecida como endolisina) que, semelhante à lisozima, hidrolisa os receptores glicosídicos na camada peptideoglicana da parede celular (BIENKOWSKA-SZEWCZYK et al., 1981). O gene $S$ é responsável por alterar a permeabilidade da membrana plasmática, permitindo assim que a endolisina se infiltre e atinja os receptores glicosídicos (SMITH et al., 1998). Já a função do gene Rz/Rzı, apesar de estar presente em fagos lambdóides de hospedeiros Gram-negativos ( $\lambda$, P22, 21 e PA-2), ainda não é claramente conhecida, mas suspeita-se que as proteínas expressas por estes genes atuem sobre a parede celular do hospedeiro (ZHANG e YOUNG, 1999; YOUNG et al., 2004).

\section{Experiências com fagoterapia em aves}

Vários estudos têm sido realizados na avaliação do uso de bacteriófagos para redução de Salmonella em aves vivas ou subprodutos avícolas. A ação fágica apresentou resultados favoráveis por via oral em pintos (FIORENTIN et al., 2005; ATTERBURY et al., 2007; ANDREATTI FILHO et al., 2007), por aspersão e em água de bebida (BORIE et al., 2008; BORIE et al., 2009). Em todos os ensaios observou-se a eliminação in vitro das amostras de Salmonella testadas, porém in vivo não se obteve os mesmos resultados, somente uma redução de UFC (unidades formadoras de colônia) intestinal, o que sinaliza que a fagoterapia em aves contra Salmonella é aplicável ainda que os resultados não tenham sido animadores.

O uso da fagoterapia também foi testado em conjunto com produtos de exclusão competitiva (TORO et al., 2005; BORIE et al., 2009). Nestes estudos os autores chegaram a índices relativamente altos de redução de unidades formadoras de colônias (UFC), mostrando que a interatividade com outros agentes biológicos é uma vantagem sobre o uso isolado de bacteriófagos, uma vez que combinam diferentes formas biológicas para confrontar a permanência da Salmonella no intestino das aves.

Recentemente a eliminação do agente foi alcançada, utilizando a associação da fagoterapia com probióticos (MARIETTO-GONÇALVES et al., 2011) em um ensaio com um bacteriófago modelo em amostras de Lactobacillus (até então os experimentos utilizaram bacteriófagos selvagens e coleção de bactérias não identificadas), comprovando que a fagoterapia em associação com outros agentes biológicos selecionados funciona.

Em subprodutos avícolas, a fagoterapia já foi testada in vitro para desinfecção em pele (GOODE et al., 2003) e carcaça (HIGGINS et al., 2005; BIELKE et al., 2007), sendo os resultados mais satisfatórios quando comparado aos testes com aves vivas obtendo-se a eliminação com maior facilidade, onde o grau de redução chega a variar entre 60 e $100 \%$. A questão atual é conseguir a eliminação de Salmonella somente com o uso de bacteriófagos em aves vivas, pois no tratamento de carcaças isso já foi demonstrado. 


\section{Considerações Finais}

A grande maioria dos estudos atuais envolvendo fagoterapia e aves apresentam como resultado apenas uma redução significativa da contaminação por Salmonella, poucos apresentaram sucesso na eliminação do agente. Somente o estudo conciliando a fagoterapia com probióticos e os que realizaram tratamento em carcaças apresentam tal feito, porém isso não reflete de forma negativa $o$ incentivo na pesquisa da fagoterapia.

O grande paradigma que existe se dá pelo fato de que in vitro todos os estudos apresentaram resultados excelentes $\mathrm{e}$ in vivo os resultados não se repetiram. Até o presente momento não se sabe o motivo dessa variação de sucesso in vitro e insucesso in vivo, mas acredita-se que exista uma relação entre a dose oferecida com a dose viável no ponto estratégico de ação. Especula-se (dados não publicados) que haja uma perda considerável na dose infectante de bacteriófagos durante toda a sua passagem ao longo do trato digestório a ponto de haver poucas unidades virais viáveis para lisar a bactéria nos cecos aviários. Logo, a determinação de uma dose infectante exata é uma meta a ser estudada. Outro fator que pode influenciar é a especificidade das amostras de bacteriófagos líticos isolados e o tempo de replicação destas amostras. Resumindo, acredita-se que exista uma relação quantidade de bacteriófagos infectantes/tempo de replicação. Logo, isso sugere que a fagoterapia continua a ser considerada como uma técnica promissora, porém, estudos aprofundados visando espécies e ciclos biológicos dos bacteriófagos devem ser realizados para uma melhor compreensão destes agentes, e com isso uma melhor aplicação e dinamização do sucesso da técnica de fagoterapia.

A fagoterapia, por ser um mecanismo biológico, conferindo melhor qualidade final ao alimento por não deixar resíduos na carne, ovos e também no ambiente, além de ser economicamente viável, quando comparada ao custo terapêutico dos quimioterápicos. Estes fatores associados à sua biosseguridade possibilitam e asseguram este rótulo de "promissor" da fagoterapia para o futuro da terapêutica no controle das salmoneloses aviárias.

\section{Referências}

1. ANDREATTI FILHO, R.L.; FERNANDES, S.A.; BORETTI, L.P.; BARROS, M.R.; DEL BEM, S.R.; FONTANA, A.; SAMPAIO, H.M.; SAVONA, E.N. Sorovares de Salmonella isolados de materiais avícolas no período de 1994 a 1999. Revista de Educação Continuada CRMV-SP, v.4, n.3, p.90-101, 2001.

2. ANDREATTI FILHO, R.L. Paratifo Aviário. In: ANDREATTI FILHO, R.L. Saúde Aviária e Doenças. São Paulo: Roca, p.96-111, 2007

3. ANDREATTI FILHO, R.L.; HIGGINS, J.P.; HIGGINS, S.E.; GAONA, G.; WOLFENDEN, A.D.; TELLEZ, G.; HARGIS; B.M. Ability of bacteriophages isolated from different sources to reduce Salmonella enterica serovar Enteritidis in vitro and in vivo. Poultry Science, v.86, n.9, p.1904-1909, 2007.
4. ATTERBURY, R.J.; VAN BERGEN, M.A.P.; ORTIZ, F.; LOVELL, M.A.; HARRIS, J.A.; DE BOER, A.; WAGENAAR, J.A.; ALLEN, V.M.; BARROW, P.A. Bacteriophage therapy to reduce Salmonella colonization of broiler chickens. Applied and Environmental Microbiology, v.73, n.14, p.4543-4549, 2007.

5. BAXA, U.; STEINBACHER, S.; MILLER, S.; WEINTRAUB, A.; HUBER, R.; SECKLER, R. Interactions of phage $\mathrm{P} 22$ tails with their cellular receptor, Salmonella O-antigen polysaccharide. Biophysical Journal, v.71, n.4, p.2040-2048, 1996.

6. BERCHIERI JÚNIOR, A.; FREITAS NETO, O.C. Salmoneloses. In: BERCHIERI JÚNIOR, A.; SILVA, E.P.; DI FÁBIO, J.; SESTI, L.; FAGNANI ZUANAZE, M.A. Doença das Aves, 2. ed. Campinas: Fundação APINCO de Ciência e Tecnologia Avícolas, 2009. p. 435-454.

7. BERGETT, P.B.; POTEETET, A.R. Structure and functions of the bacteriophage P22 tail protein. Journal of Virology, v.34, n.1, p.234-243, 1980.

8. BIELKE, L.R.; HIGGINS, S.E.; DONOGHUE, A.M.; DONOGHUE, D.J.; HARGIS, B.M.; TELLEZ, G. Use of wide-host-range bacteriophages to reduce Salmonella on poultry products. International Jounal of Poultry Science, v.6, n.10, p.754-757, 2007.

9. BIENKOWSKA-SZEWCZYK, K.; LIPINSKA, B.; TAYLOR, A. The R gene product of bacteriophage lambda is the murein transglycosylase. Molecular and General Genetics, v.184, n.1, p.111-114, 1981.

10. BIER, O. Microbiologia e Imunologia. 23. ed. São Paulo: Melhoramentos, 1984. p.1234.

11. BRADBURY, J. "My enemy's enemy is my friend" - Using phages to fight bacteria. Lancet, n.21, v.363, p.624-625, 2004.

12. BORIE, C.; ALBALA, I.; SÀNCHEZ, P.; SÁNCHEZ, M.L.; RAMÍREZ, S.; NAVARRO, C.; MORALES, M.A.; RETAMALES, J.; ROBESON, J. Bacteriophage treatment reduces Salmonella colonization of infected chickens. Avian Diseases, v.52, n.1, p.64-67, 2008.

13. BORIE, C.; SÁNCHEZ, M.L.; NAVARRO, C.; RAMÍREZ, S.; MORALES, M.A.; RETAMALES, J.; ROBESON, J. Aerosol spray treatment with bacteriophages and competitive exclusion reduces Salmonella enteritidis infection in chickens. Avian Diseases, v.53, n.2, p.250-254, 2009

14. BRADLEY, D.E. Ultrastructure of Bacteriophages and Bacteriocins. Bacteriological Reviews, v.31, n.4, p.230-314, 1967.

15. BROXMEYER, L. Bacteriophages: antibacterials with a future? Medical Hypotheses, v.62, n.6, p.889-893, 2004.

16. BULL, J.J.; PFENNIG, D.W.; WANG, I-N. Genetic detail, optimization and phage life histories. Trends in Ecology Evololution, v.19, n.2, 2004.

17. CENTERS OF DISEASES AND CONTROL. Investigation Update: Outbreak of Salmonella Typhimurium Infections, 2008-2009. Atlanta, 2009. Disponível em: <http://www.cdc.gov/salmonella/typhimurium/update.html>. Acessado em: 25 de ago. 2011.

18. CRABTREE, S.; CRONAN JUNIOR, J.E. Facile and gentle method for quantitative lysis of Escherichia coli and Salmonella typhimurium. Journal of Bacteriology, v.158, n.1, p.354-356, 1984.

19. DANIELS, D.L.; SCHROEDER, J.L.; SZYBALSKI, W.; SANGER, F.; BLATTNER, F.R. Appendix I: A molecular map of coliphage lambda. In: HENDRIX, R.W.; ROBERTS, J.W.; STAHL, F.W.; WEISBERG, R.A. (ed). Lambda II. New York: Cold Spring Harbor Laboratory Press, 1983. p.469-517.

20. DUBLANCHET, A.; FRUCIANO, E. Brève histoire de la phagothérapie. Médecine et Maladies Infectieuses, v.38, p.415-420, 2008.

21. FIORENTIN, L.; VIEIRA, N.D.; BARIONI JÚNIOR, W. Oral treatment with bacteriophages reduces the concentration of Salmonella Enteritidis PT4 in caecal contents of broilers. Avian Pathology, v.34, n.3, p.258-263, 2005.

22. GAST, R.K. Paratyphoid Infections. In: B.W. BARNES, H.J.; BEARD, C.W.; MCDOUGALD, L.R.; SAIF, Y.M. (ed). Diseases of poultry. 10. ed., Ames: lowa State University Press, 1997. p. 97-121. 
23. GARRETT, J.; FUSSELMAN, R.; HISE, J.; CHIOU, L.; SMITH-GRILLO, D.; SCHULZ, J.; YOUNG, R. Cell lysis by induction of cloned lambda lysis genes. Molecular and General Genetics, v.182, n.2, p.326-31, 1981.

24. GOODE, D.; ALLEN, V.M.; BARROW, P.A. Reduction of experimental Salmonella and Campylobacter contamination of chicken skin by application of lytic bacteriophages. Applied in Environmental Microbiology, v.69, n.8, p.5032-5036, 2003.

25. HANLON, G.W. Bacteriophages: an appraisal of their role in the treatment of bacterial infections. International Journal of Antimicrobrial Agents, v.30, p.118-128, 2007.

26. HERSKOWITZ, I.; SIGNER, E.R. A site essential for expression of all late genes in bacteriophage lambda. Journal of Molecular Biology, v.47, n.3, p.545-556, 1970.

27. HIGGINS, J.P.; HIGGINS, S.E.; GUENTHER, K.L.; HUFF, W.; DONOGHUE, A.M.; DONOGHUE, D.J.; HARGIS, B.M. Use of a specific bacteriophage treatment to reduce Salmonella in poultry products. Poultry Science, v.84, n.7, p.1141-1145, 2005.

28. HOFER, E.; SILVA FILHO, S.J.; REIS, E.M.F. Prevalência de sorovares de Salmonella isolados no Brasil. Pesquisa Veterinária Brasileira, v.17, n.2, p.55-62, 1997.

29. HUFF, W.E.; HUFF, G.R.; RATH, N.C.; BALOG, J.M.; XIE, H.; MOORE JÚNIOR, P.A.; DONOGHUE, A.M. Prevention of Escherichia coli respiratory infection in broiler chickens with bacteriophage (SPR02). Poultry Science, v.81, p.437-441, 2002.

30. HUFF, W.E.; HUFF, G.R.; RATH, N.C.; BALOG, J.M.; DONOGHUE, A.M. Alternatives to antibiotics: utilization of bacteriophage to treat colibacillosis and prevent foodborne pathogens. Poultry Science, v.84, p.655-659, 2005.

31. ISRAEL, V. A model for the adsorption of phage P22 to Salmonella typhimurium. Journal of General Virology, v.40, p.669-673, 1978.

32. JANG, B.; JUNG, Y.; LIM, D. Development of a simple cell lysis method for recombinant DNA using bacteriophage lambda lysis genes. Journal of Microbiology, v.45, n.6, p.593-596, 2007

33. JOERGER, R.D. Alternatives to antibiotcs: bacteriocins, antimicrobial peptides and bacteriophages. Poultry Science, v.82, n.4, p.640-647, 2003.

34. JUDICIAL COMMISSION. The type species of the genus Salmonella Lignieres 1900 is Salmonella enterica (ex Kauffmann and Edwards 1952) Le Minor and Popoff 1987, with the type strain LT2T, and conservation of the epithet enterica in Salmonella en terica over all earlier epithets that may be applied to this species. Opinion 80. International Journal of Systematic and Evolutionary Microbiology, v.55, p.519-520, 2005.

35. KERR, C. Bacteriophages - the new antibiotics. Lancet, n.7, v.3, p.394, 2003.

36. LENSKI, R.E. Dynamics of interations between bacteria and virulent bacteriophages. Advances in Microbial Ecology, v.10, p.1-44, 1988.

37. LENTZ, T.L. The recognition event between virus and host cell receptor: a target for antiviral agents. Journal of General Virology, v.71, n.4, p.751-766, 1990.

38. LINDBERG, A.A. Bacterial surface carbohydrates and bacteriophage adsorption. In: SUTHERLAND, I.W. (ed). Surface Carbohydrates of the Procaryotic Cell. London: Academic Press, 1977. p.289-356.

39. MANDILARA, G.; MAVRIDOU, A.; LAMBIRI, M.; VATAPOULOS, A.; RIGAS, F. The use of bacteriophages for monitoring the microbiological quality of sewage sludge. Environmental Technology, v.27, n.4, p.367-375, 2006

40. MARIETTO-GONÇALVES, G.A.; LIMA, E.T.; DONATO, T.C.; ROCHA, T.S.; ÁLVAREZ, L.E.C.; SEQUEIRA, J.L.; ANDREATTI FILHO, R.L. Eradication of Salmonella Typhimurium in broiler chicks by combined use of $\mathrm{P} 22$ bacteriophage and probiotic. Microbiology Research, v.3, n.1, p.4-9, 2011.

41. MATSUZAKI, S.; RASHEL, M.; UCHIYAMA, J.; SAKURAI, S.; UJHARA, T.; KURODA, M.; IKEUCHI, M.; TANI, T.; FUJIEDA, M.; WAKIGUCHI, H.; IMAI, S. Bacteriophage therapy: a revitalized therapy against bacterial infectious diseases. Journal of Infection and Chemotherapy, v.11, p.211-219, 2005.
42. MATTEY, M.; SPENCER, J. Bacteriophage therapy - cooked goose or Phoenix rising? Currents Opinion in Biotechnology, v.19, n.6, p.608-612, 2008.

43. NELSON, D. Phage Taxonomy: We Agree To Disagree. Journal of Bacteriology, v.186, p.7029-7031, 2004.

44. PIRISI, A. Phage therapy - advantages over antibiotics? Lancet, v.356, n.21, p.1418, 2000.

45. Preliminary FoodNet Data on the Incidence of Infection with Pathogens Transmitted Commonly Through Food - 10 States, United States, 2005. Morbidity and Mortality Weekly Report, v.55, n.14, p.392-395, 2006. disponível em: <http:// www.cdc.gov/mmwr/preview/mmwrhtml/mm5514a2.htm>. Acessado em: $25 \mathrm{de}$ ago. 2011.

46. REES, J.C.; VOORHEES, K.J. Simultaneous detection of two bacterial pathogens using bacteriophage amplification coupled with matrix-assisted laser desorption/ionization time-of-flight mass spectrometry. Rapid Communication in Mass Spectrometry, v.19, n.19, p.2757-2761, 2005

47. ROHWER, F.; EDWARDS, R. The Phage Proteomic Tree: a genome-based taxonomy for phage. Journal of Bacteriology, v.184, p.4529-4535, 2002.

48. SHELOBOLINA, E.S.; SULLIVAN, S.A.; O'NEILL, K.R.; NEVIN, K.P.; LOVLEY, D.R. "Isolation, characterization, and $\mathrm{U}(\mathrm{VI})$-reducing potential of facultatively anaerobic, acid-resistant bacterium from low-pH, nitrate- and $\mathrm{U}(\mathrm{VI})$-contaminated subsurface sediment and description of Salmonella subterranea sp. nov." Applied in Environmental Microbiology, v.70, n.5, p.2959-2965, 2004

49. SKURNIK, M.; STRAUCH, E. Phage therapy: Facts and fiction. International Journal of Medical Microbiology, v.296, n.1, p.5-14, 2006.

50. SILVA, E.N; DUARTE, A. Salmonella Enteritidis em Aves: Retrospectiva no Brasil. Brazilian Journal of Poultry Science, v.4, n.2, p.85-100, 2002.

51. SMITH, D.L.; CHANG, C.Y.; YOUNG, R. The lambda holin accumulates beyond the lethal triggering concentration under hyperexpression conditions. Gene Expression, v.7, n.1, p.39-52, 1998.

52. SULAKVELIDZE, A. Phage therapy: an attractive option for dealing with antiobioticresistant bacterial infections. Drug Discovery Today, v.10, n.12, p.807-809, 2005.

53. TAUNAY, A.E.; FERNANDES, S.A.; TAVECHIO, A.T. The role of Public Health Laboratory in the problem of salmonellosis in São Paulo State, Brazil. Revista do Instituto de Medicina Tropical de São Paulo, v.38, n.2, p.119-129, 1996.

54. TAVECHIO, A.T.; FERNANDES, S.A.; NEVES, B.C.; DIAS, A.M.G.; IRINO, K. Changing patterns of Salmonella serovars: increase of Salmonella enteritidis in São Paulo, Brazil. Revista do Instituto de Medicina Tropical de São Paulo, v.38, n.5, p.315-322, 1996

55. TOOD, E.C.D. Epidemiology of the foodborne diseases: a worldwide review. World Health Statistics Quaterly, v.50, n.1-2, p.30-50, 1997.

56. TORO, H.; PRICE S.B.; MCKEE, S.; HOERR, F.J.; KREHLING, J.; PERDUE, M.; BAUERMEISTER, L. Use of bacteriophages in combination with competitive exclusion to reduce Salmonella from infected chicken. Avian Diseases, v.49, n.1, p.118-124, 2005

57. ZANCAN, F.T.; BERCHIERI JÚNIOR, A.; FERNANDES, S.A.; GAMA, N.M.S.Q. Salmonella spp investigation in transport boxes of day-old birds. Brazilian Journal of Microbiology, v.31, n.3, p.230-232, 2000.

58. ZHANG, N.; YOUNG, R. Complementation and characterization of the nested Rz and Rz1 reading frames in the genome of bacteriophage lambda. Molecular and General Genetics, v.262, n.4-5, p.659-667, 1999.

59. YOUNG, R. Bacteriophage lysis: mechanism and regulation. Microbiological Reviews, v.56, n.3, p.430-481, 1992

60. YOUNG, R.; WANG, I-N.; ROOF, W.D. Phages will out: strategies of host cell lysis. Trends in Microbiology, v.8, n.3, 2000. 